connected with its faculty of being able to crystallise in more than one modification.

With regard to the possibility of examining the structure of twinned crystals by means of X-rays, Prof. Friedel fears ${ }^{8}$ that the structure arrived at in this way will have an illusory value, in particular because it will relate to an incorrect lattice unit, namely, the lattice unit underlying the whole twin structure, which may be a multiple of the real unit cell of the untwinned crystal. While not in the least denying the presence of such a multiple unit, we deduced from our considerations ${ }^{9}$ that, if indeed the X-ray investigator did find an incorrect unit cell, the danger would be greater that he would find a submultiple of the true cell than a multiple.

It is interesting to note that precisely this anticipation occurred in a recent $\mathrm{X}$-ray investigation of crystals of the mineral boleite by B. Gossner and M. Arm, ${ }^{10}$ who attributed to these crystals a cubic unit cell with side-length $a=15 \cdot 40 \mathrm{~A}$. This statement was in contradiction with a crystallographic study of this mineral by Prof. Friedel (dating from as early as $1906^{11}$ ), who from an examination of the cleavage of boleite crystals concluded that the cubic appearance is only a consequence of mimetic twinning of perpendicularly crossing biaxial quadratic lamellæ with an axial ratio $c: a$ very close to the value four. Now, from a careful $\mathrm{X}$-ray investigation of a small untwinned birefringent fragment of a crystal of boleite, R. Hocart ${ }^{12}$ in Prof. Friedel's laboratory could show that on his rotation photographs about the $c$-axis of the crystal some faint layer lines appeared, lying between those abserved by Gossner and Arm, from which it followed that the $c$-axis of the unit cell of the untwinned crystal is $62 \mathrm{~A}$., that is, practically four times as great as the $a$-axis Without discussing in how far the weakness of these interadjacent layer-lines on Hocart's photographs is still an indication for the possibility of subdividing the true unit cell of boleite in four structurally closely related sub-cells, ${ }^{13}$ their presence on one hand, confirms beautifully Prof. Friedel's prediction of the axia ratio of the untwinned crystal; on the other hand, it is in striking agreement with my own prediction about the danger of finding by $\mathrm{X}$-rays a sub-multiple of the true unit cell instead of a multiple.

$$
\text { W. G. Burgers. }
$$

Natuurkundig Laboratorium der

N. V. Philips' Gloeilampenfabrieken, Eindhoven, Holland, Jan. 18.

W. G. Burgers, Proc. Roy. Soc., A, 116, 553; 1927.

2 "Au sujet d'un Mémoire de M. W. G. Burgers sur les cristaux uniaxes à pouvoir rotatoire ", Comptes rendus, 186, 1788; 1928

3 Compare, for example, the explanation of some twin structures exhibited by quartz crystals, by Sir W. H. Bragg and R. F. Gibbs, Proc. Roy. Soc., A, 109, 405; 1925.

W. L. Bragg, Proc. Roy. Soc., A, 105, 16; 1924 1928.

8.

${ }_{8}$ It may be remarked in this connexion that even Prof. Friedel himself, notwithstanding his definite statement about the cause of twinning quoted above, has made similar remarks in other passages of his treatises, as, for example, in "Leçons de crist.", p. 459.

Z. Krist., 80, 355; 1931 .

" "Lecons de cristallographie ", pp. 392-398; compare also Comptes rendus, 182, $741 ; 1926$.

- Proc. Roy. Soc., loc. cit., pp. 560-561.

10 Z. Krist., 72, $218 ; 1929$

11 See $Z$. Krist., 73, 147; 1930

12 Z. Krist., 74, $20 ; 1930$

3 Compare, for example, W. H. Bragg, "An Introduction to Crystal Analysis" (London, G. Bell, 1928, pp. 134 and following); also W. T. Astbury, Proc. Roy. Soc., A, 112, $448 ; 1926$.

\section{Polarisation of Downcoming Wireless Waves}

IN a method which has previously been used ${ }^{1}$ for determining the state of polarisation of downcoming wireless waves, the frequency of a transmitter was varied so as to produce interference maxima and minima at the receiver in the well-known way. By analysing the signal variations at the receiver, it was possible to deduce the state of polarisation of the downcoming waves. The method suffered from two disadvantages, as follows :

(1) In order to interpret the results, it was necessary to assume that the intensity and state of polarisation of the waves had remained constant during the making of the frequency change. This restricted the observations to a period just before sunrise, when the downcoming wave was found to be sufficiently constant.

(2) It was possible to carry out the experiments only in conjunction with special transmitting stations such that the requisite frequency change could be made. This restricted very much the geographical locations of the transmitting stations.

We have now developed a method of observation which gives a pictorial representation of the state of polarisation on an oscillograph screen, and can be used to analyse the wave from any transmitter emitting a steady or a modulated wave. It may also be used when the nature of the polarisation is changing rapidly; so the two objections to the original method are removed.

In the new method, the normally polarised and ab. normally polarised components of the downcoming wave are received on two separate aerial systems, and, after being amplified, are applied to opposite pairs of plates of a cathode ray oscillograph. The ground wave may be eliminated by the use of suitable aerial systems. The phase relations in the receivers are adjusted correctly by employing a small local transmitter placed in such a position that it induces into both systems. The sense of rotation of an elliptically polarised downcoming wave is determined by momentarily detuning one of the amplifiers slightly.

The apparatus has been used to investigate the downcoming waves from the London National transmitter received at Cambridge during the evening hours from sunset until midnight. The distance of propagation is $56 \mathrm{~km}$. and the wave-length $216 \mathrm{~m}$. It is found that the type of polarisation changes very rapidlyan appreciable change taking place in half a second. The commonest form of polarisation observed approximates to a circle, but straight lines and narrow ellipses often inclined to the vertical plane of propagation are frequently observed. Although the type of polarisation varies considerably, it has been found that the sense of rotation of the figure is always the same. Observations on five different nights and on three different settings of the calibration apparatus have shown that the sense of rotation is anticlockwise if we look along the ray in the direction of travel.

These preliminary results therefore confirm the previous results of Appleton and Ratcliffe, and lend support to the theory outlined by them and recently mentioned by Prof. Appleton. ${ }^{2}$

\section{J. A. Ratchiffe.}

The Cavendish Laboratory, Cambridge, Feb. 5.

1 Appleton and Rateliffe, Proc. Roy. Soc., A, 117, 576; 1928.

2 NATURE, 128, 1037, Dec. 19, 1931.

\section{Perception of Gravity by Roots of Vicia Faba}

UNTIl recent years it was a generally accepted view that the region of perception of gravitational stimuli in roots was the extreme tip of the root. Cholodny, ${ }^{1}$ however, performed experiments in which he replaced the root tip in maize by the tip of the coleoptile, and the fact that a positive curvature was still obtained suggested that the function of the root tip might not be so simple as had hitherto been supposed. More

No. 3253, VoL. 129] 